Eur. J. Clin. Chem. Clin. Biochem.

Vol. 30, 1992, pp. 15-19

C 1992 Walter de Gruyter \& Co.

Berlin · New York

\title{
Ultrafiltrate Analysis Confirms the Specificity of the Selected Method for Plasma Ammonia Determination
}

\author{
By F. da Fonseca-Wollheim
}

Zentrallaboratorium, Behring-Krankenhaus Berlin-Zehlendorf

(Received September 25/November 7, 1991)

Summary: The specificity of the direct enzymatic determination of plasma ammonia has hitherto not been unequivocally confirmed, because a suitable comparison method was lacking. Therefore a method variant was elaborated, which includes ultrafiltration to eliminate the high-molecular-mass components regarded as potential sources of unspecifity in the direct measurement procedure according to Rattliff, C. R. \& Hall, F. F. (Select. Meth. Clin. Chem. 9, 85-90 (1982)). As the the distribution of ammonia during plasma ultrafiltration is markedly influenced by $\mathrm{pH}$ and protein concentration, plasma $\mathrm{pH}$ is adjusted to 5.5 where the distribution ratio is 1 and nearly independent of actual protein concentration. Acidification significantly diminishes the spontaneous increase of ammonia in plasma at $2-4{ }^{\circ} \mathrm{C}$, and the plasma ultrafiltrate is virtually stable. Taking into consideration the slow ammonia formation during sample preparation, excellent agreement was found between ammonia concentrations measured in plasma and in plasma ultrafiltrate, using samples with an apparently normal matrix $(n=30)$, dysproteinaemia $(n=32)$ or paraproteinaemia $(n=8)$. Our data show that the protein matrix of the sample does not cause significant unspecificity in the direct "endpoint" procedure for ammonia determination nor does it affect imprecision. In samples with added bilirubin (up to $252 \mu \mathrm{mol} / \mathrm{l}$ ), haemolysate (haemoglobin up to $3.87 \mathrm{~g} / \mathrm{l}$ ) or lipid emulsion (triacylglycerol up to $3.86 \mathrm{mmol} / \mathrm{l}$ ) ammonia values determined directly in plasma differed maximally by $4 \%$ from ultrafiltrate values. A simplified procedure for the ultrafiltration of plasma may be used routinely in clinical service in cases of grossly icteric, haemolytic or turbid samples.

\section{Introduction}

Introducing a simplified method for direct measurement of an analyte in plasma without deproteinization should include careful comparison of the results with those obtained with a more laborious method of proven accuracy. In the direct enzymatic determination of plasma ammonia concentration, using NADPH as coenzyme (1), comparison studies using different variants of the ion exchange method have given divergent results $(2,3)$. The enzymatic method for ammonia determination with deproteinization by $\mathrm{HClO}_{4}(4)$ seems not to be aceptable for reference, because the addition of strong acid may cause ammonia formation in the sample matrix (5). In the present work it is shown that ultrafiltrates from plasma are useful a) for evaluating the direct ammonia method and

b) for reliable routine measurement of plasma ammonia in samples with a grossly abnormal matrix.

\section{Materials and Methods}

Reagents

The reagents for enzymatic ammonia determination (6) were from Boehringer Mannheim GmbH, Mannheim, Germany. Bilirubin, cat. No. 23519.0100, was purchased from Merck, Darmstadt, Germany. The fat emulsion used in interference experiments was $20 \%$ Intralipid ${ }^{\circledR}$ obtained from Pfrimmer Kabi GmbH, Erlangen (Germany). Purified serum albumin, cat. No. OHRD 20/21, was obtained from Behringwerke, Marburg, Germany. The other chemicals used were reagent grade. 


\section{Sample selection and preparation}

Blood samples anticoagulated with dipotassium EDTA, $4 \mathrm{mmol} / \mathrm{l}$, were taken from the workload of our haematological laboratory. Plasma samples were obtained by centrifugation at $2000 \mathrm{~g}$ (10 minutes, room temperature).

\section{Samples with normal matrix}

Thirty plasma samples with normal matrix were selected according to the following criteria: No abnormal appearance (colour, turbidity); values within accepted reference limits for activity of alanine aminotransferase, concentrations of total bilirubin, total protein, triacylglycerol, and electrophoretic serum protein fractions using cellulose acetate separation technique after fibrinogen removal with bathroxobin. Samples with increased ammonia concentrations were obtained by prolonged standing of whole blood specimens prior to centrifugation.

\section{Samples with abnormal protein matrix}

To study the influence of an abnormal protein matrix $32 \mathrm{spec}-$ imens with abnormal electrophoretic fraction value(s) were selected. Additionally, 8 specimens exhibiting monoclonal bands in electrophoresis verified by immunofixation were included in the study.

\section{Preparation of samples with added interferents}

Three units of citrated fresh frozen plasma were pooled. Portions $(2 \mathrm{ml})$ were chromatographied on several Sephadex G-25 $\mathrm{M}$ minicolumns (Column PD-10; Pharmacia, Uppsala, Sweden) using a mixture containing $0.15 \mathrm{~mol} / \mathrm{l} \mathrm{NaCl}$ and $10 \mathrm{mmol} / \mathrm{l}$ sodium phosphate $\left(\mathrm{pH} 7.0,20^{\circ} \mathrm{C}\right)$ as the eluent. Ammonium chloride solution was added to a final concentration of 80 $\mu \mathrm{mol} / 1$. The protein concentration was $49 \mathrm{~g} / \mathrm{l}$. Portions of the pool were individually spiked with bilirubin, haemolysate or Intralipid ${ }^{\circledR}$ according to Glick et al. (7). The following volume fractions of spiked pool were mixed with unmodified pool: 0 , $0.25,0.5,0.75$ and 1 . The resulting concentration ranges were: bilirubin $6-252 \mu \mathrm{mol} / \mathrm{l}$; haemoglobin $0.02-3.90 \mathrm{~g} / \mathrm{l}$; triacylglycerol $0.85-3.90 \mathrm{mmol} / 1$

\section{Adjustment of plasma $\mathrm{pH}$ before ultrafiltration}

Using multipipette (Eppendorf-Netheler-Hinz GmbH, Hamburg, Germany), $0.32 \mathrm{ml} \mathrm{HCl}(0.1 \mathrm{~mol} / \mathrm{l})$, chilled in an icewater bath, was added quickly with vigorous stirring in $20 \mu \mathrm{l}$ aliquots to $1 \mathrm{ml}$ plasma $\left(0^{\circ} \mathrm{C}\right)$. The resulting $\mathrm{pH}$ was between 5.5 and $5.6\left(0^{\circ} \mathrm{C}\right)$

\section{Ultrafiltration}

For ultrafiltration, $2 \mathrm{ml}$ of the protein-containing solution were placed on the bottom of a Centrisart I (Cat. No. 12349-E, Sartorius GmbH W-3400 Göttingen) centrifuge tube. After inserting the filtrate collector carrying the semipermeable membrane (cellulose triacetate; cutoff $M_{\mathrm{r}} \sim 20000$ ) the tube was centrifuged in a swing head rotor for $40-60$ minutes $(2000 \mathrm{~g}$, $2-4{ }^{\circ} \mathrm{C}$ ) resulting in $\sim 0.5 \mathrm{ml}$ colourless filtrate. As the disposable filtrate collectors were found to be contaminated with ammonia, they were washed with demineralized water prior to use. Adherent fluid was removed by brief centrifugation in an inverted position.

\section{Analytical procedures}

Ammonia in plasma and ultrafiltrates was determined with the enzymatic "endpoint" method (1) modified according to the procedure given in Selected Methods (8). This was adapted by us for the Abbott VP Series II Bichromatic Analyzer (Abbott Laboratories, Irving, TX, USA), and it shows good analytical performance (6). The final dilution of the sample in the reaction mixture is $1: 3$. The imprecision of ammonia determination, as estimated from 50 double determinations in plasma and plasma ultrafiltrates, was nearly identical with unselected patient samples containing ammonia concentrations between 22 and 87 $\mu \mathrm{mol} / \mathrm{l}$ (mean standard deviation with plasma 1.17, with ultrafiltrates $1.20 \mu \mathrm{mol} / \mathrm{l}$ ). All measurements with unknown samples were performed as triplicates. In comparison studies, ammonia concentrations were measured within the same run in

a) untreated plasma,

b) acidified plasma before centrifugation,

c) acidified plasma after centrifugation,

d) plasma ultrafiltrates.

Until measurement, the samples a) and b) were stored at $-38^{\circ} \mathrm{C}$ for preservation (6)

P-alanine aminotransferase'), P-total bilirubin, P-triacylglycerol and total protein in plasma or bovine albumin solutions were measured with a Model 704 automated analyzer from Hitach Ltd., Tokyo, Japan, with procedures and system reagents from Boehringer Mannheim GmbH, Mannheim, Germany. Plasma haemoglobin was determined by direct spectrophotometry (9) using an Uvikon 810 spectrophotometer (Kontron Instruments, Zurich, Switzerland)

\section{Results}

Distribution of ammonia in the ultrafiltration process

Distribution studies using samples of pooled human plasma at different $\mathrm{pH}$ spiked with $\mathrm{NH}_{4} \mathrm{Cl}(1 \mathrm{mmol} / \mathrm{l})$ show that ultrafiltration of ammonia is clearly $\mathrm{pH}$ dependent (fig. 1). At pH 5.5 an equal distribution is observed while below pH 5.5 ammonia is overrepresented in the ultrafiltrate. At $\mathrm{pH} 8$ the ratio reaches a minimum. The $\mathrm{pH}$ effects in the presence of bovine serum albumin are similar (fig. 1). When the concentrations of bovine albumin were varied between 0 and $100 \mathrm{~g} / \mathrm{l}$, the distribution ratios obtained ranged between 1.011 and 1.214 at $\mathrm{pH} 3$ and between 0.986 and 0.917 at $\mathrm{pH} 8$, while at $\mathrm{pH} 5.5$ the ratios where 0.987 , $0.988,0.992$ and 1.011 in the presence of $0,20,60$, or $100 \mathrm{~g} / \mathrm{l}$ albumin, respectively. It follows that adjusting the sample $\mathrm{pH}$ to 5.5 will result in ammonia concentrations in ultrafiltrate in close agreement with those in the plasma.

\section{1) Enzymes:}

Alanine aminotransferase, $L$-alanine:2-oxoglutarate aminotransferase, EC 2.6.1.2

$\gamma$-Glutamyltransferase, $\gamma$-glutamyl-peptide : aminoacid $\gamma$-glutamyltransferase, EC 2.3.2.2

Glutamate dehydrogenase, $L$-glutamate: NAD(P) oxidoreductase (deaminating), EC 1.4.1.3

Glutaminase, $L$-glutamine amidohydrolase, EC 3.5.1.2 


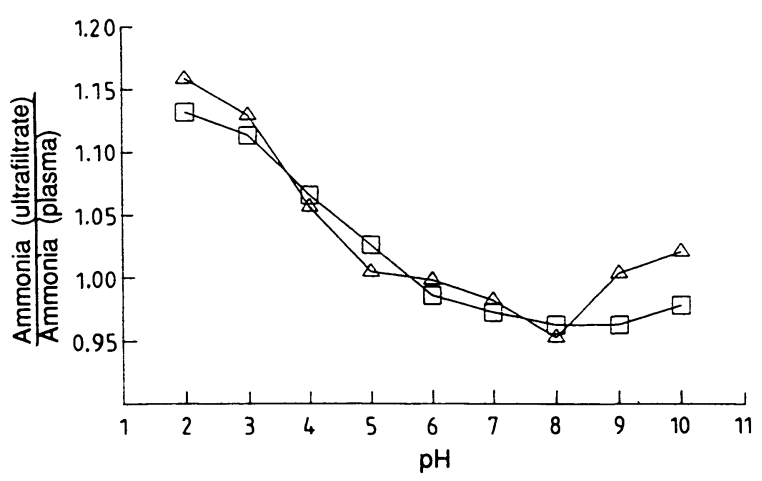

Fig. 1. Distribution of $1 \mathrm{mmol} / \mathrm{l}$ ammonia during ultrafiltration of protein solutions at various $\mathrm{pH}$-values. The protein concentrations were: human plasma $63.4 \mathrm{~g} / \mathrm{l}(\square-\square)$; bovine albumin solution $63.5 \mathrm{~g} / \mathrm{l}(\triangle-\triangle)$

\section{Ammonia formation during sample prepara- tion}

Preliminary experiments showed that $0.32 \mathrm{ml}$ diluted $\mathrm{HCl}(0.1 \mathrm{~mol} / \mathrm{l})$ per ml EDTA plasma are required to adjust the $\mathrm{pH}$ to about $5.5\left(0^{\circ} \mathrm{C}\right)$. This step appears to be rather critical as an increase in plasma ammonia concentration after addition of strong acid may be expected (5). Under the conditions chosen (plasma sample and acid chilled to $0{ }^{\circ} \mathrm{C}$, addition of the acid in small portions with vigorous mixing), a substantial increase of the ammonia concentration due to decomposition of labile matrix compounds was avoided (tab.1, columns A and B). Results showed less agreement if more concentrated acid was applied or if mixing was less efficient.

Tab. 1. Ammonia concentrations in plasma and plasma ultrafiltrates $(\mu \mathrm{mol} / 1)$; effect of acidification and time on plasma values.

A, plasma with unmodified $\mathrm{pH}$ (volume correction with $0.15 \mathrm{~mol} / 1 \mathrm{NaCl}$ );

$\mathrm{B}$, plasma after adjustment to $\mathrm{pH} 5.5$;

C, plasma ultrafiltrate;

$\mathrm{D}$, plasma after adjustment to $\mathrm{pH} 5.5$ and storage at $2-4{ }^{\circ} \mathrm{C}$ during ultrafiltration,

$\mathrm{E}$, average of $\mathrm{B}$ and $\mathrm{D}$ used in regression analysis (see fig. 2).

For selection criteria for specimens with "normal" and "abnormal" matrix see "Methods".

\begin{tabular}{lccccl}
\hline Matrix & $\mathrm{A}$ & $\mathrm{B}$ & $\mathrm{C}$ & $\mathrm{D}$ & $\mathrm{E}$ \\
\hline Normal protein matrix & $(\mathrm{n}=30)$ & & & & \\
$\overline{\mathrm{x}}$ & 38.75 & 39.58 & 40.46 & 41.21 & 40.39 \\
Median & 31.5 & $31.0^{\mathrm{a}}$ & $32.3^{\mathrm{b}}$ & $32.8^{\mathrm{c}}$ & 31.7 \\
$\mathrm{~s}$ & 18.38 & 18.51 & 18.64 & 18.22 & 18.34 \\
Abnormal protein matrix & $(\mathrm{n}=32)$ & & & \\
$\overline{\mathrm{x}}$ & 59.55 & 59.14 & 60.20 & 60.44 & 59.80 \\
Median & 47.6 & $48.9^{\mathrm{d}}$ & $47.4^{\mathrm{b}}$ & $49.5^{\mathrm{c}}$ & 48.5 \\
$\mathrm{~s}$ & 31.13 & 29.03 & 29.37 & 29.72 & 29.36
\end{tabular}

Significantly different from A $(\mathrm{p}<0.05)$.

Not significantly different from $E$.

Significantly different from B ( $p<0.01)$.

Not significantly different from A.

a-d Wilcoxon signed ranks test.
As the production of a sufficient volume of plasma ultrafiltrate at $2-4{ }^{\circ} \mathrm{C}$ took up to 1 hour the spontaneous increase of ammonia in the samples had to be taken into consideration (tab. 1, columns B and D). Fortunately, the ammonia formation rate of EDTA plasma was reduced by a factor of 3 by adjusting the $\mathrm{pH}$ to 5.5 (tab. 2). Plasma ultrafiltrate obtained at $\mathrm{pH} 5.5$ is about tenfold more stable than neutral EDTA plasma (tab. 2).

Tab. 2. Increase in ammonia concentration ( $\mu \mathrm{mol} / \mathrm{l})$ during storage for 20 hours at $2-4{ }^{\circ} \mathrm{C}$. Randomly selected plasma specimens $(n=10)$

\begin{tabular}{|c|c|c|c|}
\hline & $\begin{array}{l}\text { Plasma } \\
\mathrm{pH} \sim 7\end{array}$ & $\begin{array}{l}\text { Plasma } \\
\text { pH } 5.5\end{array}$ & $\begin{array}{l}\text { Ultra- } \\
\text { filtrates } \\
\mathrm{pH} 5.5\end{array}$ \\
\hline$\overline{\mathrm{x}}$ & 14.37 & 4.68 & 1.55 \\
\hline Median & 13.7 & $3.9^{\mathrm{a}}$ & $1.7^{\mathrm{b}}$ \\
\hline $\mathrm{s}$ & 7.57 & 1.74 & 1.46 \\
\hline Minimum & 5.7 & 2.7 & -1.1 \\
\hline Maximum & 30.5 & 7.8 & 4.5 \\
\hline
\end{tabular}

Significantly different from plasma at $\mathrm{pH} \sim 7(\mathrm{p}<0.01)$.

b Significantly different from plasma at $\mathrm{pH} 5.5(\mathrm{p}<0.01)$.

a,b Wilcoxon signed ranks test.

Comparison study with samples without obvious matrix abnormalities

With 30 samples without obvious matrix abnormalities (see "Methods") a good agreement between measured values of ammonia concentration in plasma ultrafiltrate ( $\mathrm{x}$ ) and plasma (y) was found. Linear regression analysis yielded: $\mathrm{a}=0.64 \mu \mathrm{mol} / 1, \mathrm{~b}=0.98$, $\mathrm{r}=0.998$ (fig. 2).

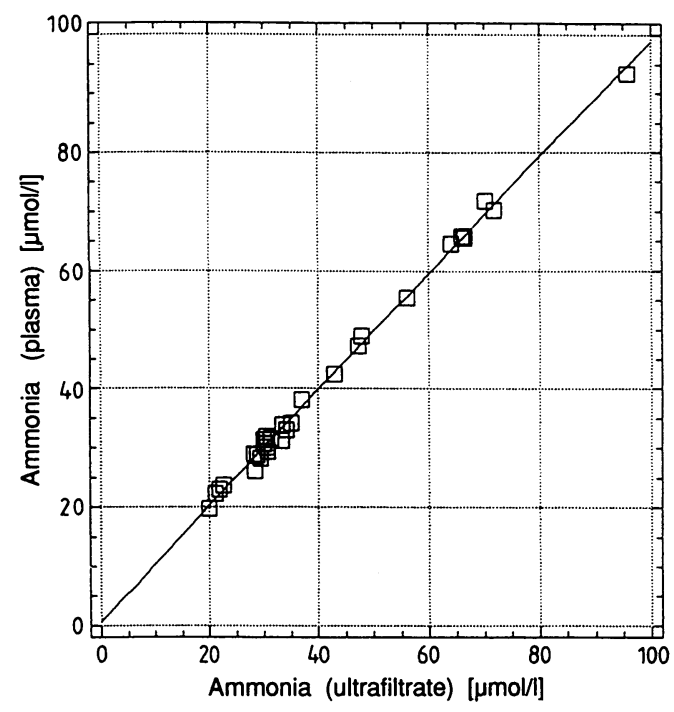

Fig. 2. Correlation of ammonia values measured in plasma and plasma ultrafiltrates. Samples without obvious matrix abnormalities (cf. tab. 1) 


\section{Comparison studies with abnormal samples}

Direct measurement of ammonia concentration might be influenced by a pathological protein matrix of the sample, e.g. by causing inconstant background absorbance. Therefore, the results of ammonia determination in plasma $(y)$ and ultrafiltrates $(x)$ were compared in 32 samples exhibiting dysproteinaemia. Again regression analysis showed good agreement $(\mathrm{a}=-0.29 \mu \mathrm{mol} / \mathrm{l} ; \mathrm{b}=1.00 ; \mathrm{r}=0.998$. In 8 cases of paraproteinaemia, including the types $\operatorname{IgA} / \kappa$, $\operatorname{IgG} / \kappa, \operatorname{IgG} / \lambda$, and $\operatorname{IgM} / \kappa$, the average ratio of ammonia concentrations determined in plasma and ultrafiltrate was 1.00 (range: $0.96-1.03$ ).

Human pool plasma with different concentrations of added interferents (bilirubin, haemolysate, triacylglycerol emulsion, see "Methods") was subjected to ultrafiltration. The ultrafiltrates were colourless and clear in all instances. The ratio between measured ammonia concentrations in plasma and ultrafiltrates remained close to 1.0 (range: $1.02-0.96$ ) with icteric (plasma bilirubin up to $252 \mu \mathrm{mol} / \mathrm{l}$ ), haemolytic (plasma haemoglobin up to $3.9 \mathrm{~g} / \mathrm{l}$ ) or lipaemic samples (triacylglycerol up to $3.9 \mathrm{mmol} / \mathrm{l}$ ), indicating a good linearity of the spectrophotometer used.

\section{Discussion}

\section{Distribution of ammonia during ultra- filtration}

At acidic and neutral $\mathrm{pH}$ ammonia mainly exists as a charged ion, the $\mathrm{p} K_{\mathrm{a}}$ of $\mathrm{NH}_{4}^{+}$being $\approx 9.3$ at room temperature (10). Therefore its distribution is subject to the Gibbs-Donnan effect caused by non-diffusible charged macromolecules (fig. 1). As the charge of proteins depends on the solution $\mathrm{pH}$, opposite effects are observed if the $\mathrm{pH}$ is varied over a broad range on both sides of the isoelectric point of the protein concerned. The distribution ratio moves to 1 at higher $\mathrm{pH}$ as the fraction of uncharged ammonia increases (fig. 1). The high ammonia concentration chosen in the experiments ensured that calculated ratios were based on true ammonia concentrations, as continuous ammonia formation in the sample is negligible. Due to the volatility of uncharged ammonia, the analytical data obtained beyond $\mathrm{pH} 9$ appeared to be less reliable.

In addition to charge effects it has to be considered that the concentration of a low-molecular mass component in the ultrafiltrate is expected to be about $5 \%$ higher than in the plasma, due to the volume occupied by the plasma proteins; this has been shown for serum creatinine (11). Therefore, the empirically determined $\mathrm{pH}$ for a 1:1 distribution of ammonia (fig. 1) will not coincide exactly with the global isoelectric point of the proteins contained in plasma.

\section{Increase of ammonia during ultrafiltration}

Besides distribution problems, the effects of slow spontaneous ammonia formation in plasma $(6,12)$ during the procedure had to be carefully controlled. Acidification improved the stability of the specimen by a factor of 3 (tab. 2); however, a significant increase during the course of ultrafiltration still had to be considered with both "normal" and "abnormal" plasma samples ( $p<0.01$, tab. 1 columns B and D). Accordingly, it appeared to be appropriate to compare the values of ammonia concentration in ultrafiltrate with the average of ammonia concentrations measured in plasma before and after ultrafiltration.

As ultrafiltrate showed much better stability than plasma (tab. 2), the ammonia concentration during the ultrafiltration can be regarded as constant. The better stability of ultrafiltrate was expected, as it has been shown that the increased rate of ammonia formation in plasma is correlated to certain enzyme activities in the sample (6), especially $\gamma$-glutamyltransferase $^{1}$ ) acting as glutaminase ${ }^{1}$ ) (12), which are eliminated during ultrafiltration.

\section{Comparison studies}

The main task of this work was the evaluation of the selected method for direct determination of plasma ammonia (8), by comparing results with those obtained after deproteinization under carefully controlled conditions. Although glutamate dehydrogenase $^{1}$ ) is specific for ammonia (4), some analytical error caused by the plasma proteins contained in the reaction mixture (final dilution of sample solely $1: 3$ ) has so far not been excluded. Possible sources of error are: non-specific oxidation of the coenzyme, deaminating or deamidating reactions, and inconstant background absorbance caused by the sample matrix.

Indeed, most of the comparison studies described in the literature, using several variants of ion exchange techniques for reference, have given unsatisfactory results in regression analysis with large intercepts (2, 3). However, from the present study, which shows nearly ideal results in linear regression analysis (fig. 2), it can be concluded that the protein matrix in direct measurement does not affect results to a meassurable extent. So far this has only been inferred from the direct spectrophotometric observation of the course of the reaction; the non-specific oxidation of coenzyme is much less when NADPH is used instead of NADH $(1,13)$. Our results confirm that the rela- 
tively laborious and time consuming "endpoint" procedure including two additions of enzyme solution and three absorbance readings $(6,8)$ gives highly accurate results. The unsatisfactory results of earlier comparison studies appear to be caused by insufficient accuracy of the ion exchange methods used for reference $(2,3)$. It should be pointed out that our results apply also for clinical specimens from patients with dysproteinaemia or paraproteinaemia.

Interference by bilirubin, haemolysis and turbidity

To study the effect of added bilirubin solution, haemolysate and lipid emulsion (7) on the measuring system, ultrafiltrates appear to be very useful for reference, as the ultrafiltrates remain free from the interferents but contain additional ammonia from the added materials. The ratio of measured ammonia concentrations was kept close to 1 over a broad range of added interferents (see "Results"). As with simple spectrophotometers much worse performance was observed by us (due to insufficient linearity at high

\section{References}

1. da Fonseca-Wollheim, F. (1973) Direct determination of plasma ammonia without deproteinisation. An improved enzymic determination of plasma ammonia, II. J. Clin. Chem. Clin. Biochem. 11, 426-431.

2. Doumas, B. T., Hause, L. L., Sciacca, R. D., Jemdrzejczak, B., Foreback, C. C., Hoover, J. D., Spencer, W. W. \& Smock, P. L. (1979) Performance of the Du Pont aca ammonia method. Clin. Chem. 25, 175-178.

3. Wu, J., Ash, O. \& Mao, E. (1978) Modified micro-scale enzymatic method for plasma ammonia in newborn and pediatric patients; comparison with a modified cation-exchange procedure. Clin. Chem. 24, 2172-2175.

4. Fawaz, G. \& von Dahl, K. (1963) The enzymatic estimation of ammonia in tissues and body fluids. Leban. Med. J. 16, $169-174$.

5. Proelss, H. F. \& Wright, B. W. (1973) Rapid determination of ammonia in a perchloric acid supernate from blood, by use of an ammonia-specific electrode. Clin. Chem. 19, $1162-1169$.

6. da Fonseca-Wollheim, F. (1990) Preanalytical increase of ammonia in blood specimens from healthy subjects. Clin. Chem. 36, 1483-1487.

7. Glick, M. R., Ryder, K. W. \& Jackson, S. A. (1986) Graphical comparisons of interferences in clinical chemistry instrumentation. Clin. Chem. 32, 470-475. absorbance, data not shown) general conclusions should not be derived.

Analysis of ultrafiltrate may be useful for the routine measurement of plasma ammonia, e. g. in pronounced hyperbilirubinaemia, when the background absorbance exceeds the measuring range of the available spectrophotometer. Though acidification of the sample to $\mathrm{pH} 5.5$ before ultrafiltration is optimal for the purpose of method comparison studies, this step should be abandoned under routine conditions. The potential error from omitting acidification is low (see fig. 1) compared with the potential error from nonoptimal addition of the $\mathrm{HCl}$ (see "Methods"). To increase the stability of the neutral plasma sample during ultrafiltration, the glutaminase activity should be inhibited by adding $5 \mathrm{mmol} / \mathrm{l}$ serine and $2 \mathrm{mmol} / \mathrm{l}$ neutral sodium borate, as generally recommended for the preservation of clinical samples (12).

\section{Acknowledgement}

The exceptional technical assistance of Mrs. C. Nilgen is gratefully acknowledged. The work was supported by Abbott Laboratories by granting a VP Bichromatic Analyzer.

8. Rattliff, C. R. \& Hall, F. F. (1982) Ammonia in plasma, enzymic procedure. Select. Meth. Clin. Chem. 9, 85-90.

9. Noe, D. A., Weedn, V. \& Bell, W. R. (1984) Direct spectrophotemetry of serum hemoglobin: An Allen correction compared with three-wavelength polychromatic analysis. Clin. Chem. 30, 627-630.

10. Bachmann, C. (1978) Stickstoffwechsel. In: Klinische Chemie, 4th edn. (Richterich, R. \& Colombo, J. P., eds.) pp. 319-338, Karger, Basel.

11. da Fonseca-Wollheim, F., Heinze, K.-G., Lomsky, K. \& Schreiner, H. (1988) Serum ultrafiltration for the elimination of endogenous interfering substances in creatinine determination. J. Clin. Chem. Clin. Biochem. 26, 523-525.

12. da Fonseca-Wollheim, F. (1990) Deamidation of glutamine by increased $\gamma$-glutamyltransferase is a source of rapid ammonia formation in blood and plasma specimens. Clin. Chem. 36, 1479-1482.

13. da Fonseca-Wollheim, F. (1973) The significance of hydrogen ion concentration and the addition of ADP in the determination of ammonia with glutamate dehydrogenase. An improved enzymic determination of plasma ammonia I. J. Clin. Chem. Clin. Biochem. 11, 421-425.

Dr. med. F. da Fonseca-Wollheim Zentrallaboratorium Behring-Krankenhaus Berlin-Zehlendorf Gimpelsteig 3-5

W-1000 Berlin 37

Bundesrepublik Deutschland 
